\title{
Gamma-aminobutyric acid in the genital tract of the rat during the oestrous cycle
}

\author{
P. Louzan, M. G. P. Gallardo and J. H. Tramezzani \\ Institute of Neurobiology, Serrano 665, 1414 Buenos Aires, Argentina
}

\begin{abstract}
Summary. The highest values of $\gamma$-aminobutyric acid (GABA) in the genital tract of the rat at different stages of the oestrous cycle were found in the oviduct $(3 \cdot 5-7 \mu \mathrm{g} / \mathrm{mg}$ protein) and the lowest in the ovary (50-100 $\mathrm{ng} / \mathrm{mg}$ protein). The values for uterus and vagina ranged between 80 and $150 \mathrm{ng} / \mathrm{mg}$ protein. GABA $(10-30 \mathrm{ng} / \mu \mathrm{l})$ was also found in fluid in the ovarian bursa. At 11:00 h, on the day of oestrus, GABA content increased in the ovaries but values in the oviducts were maximal at 11:00 h on the day of pro-oestrus. Variations in GABA content of the vagina were also found. Uterine cervix or uterine horn showed no changes during the oestrous cycle. The GABA content was not uniform throughout the oviduct: the highest values were found in the portion next to the ovary. At 10 days after removal of the right oviduct, GABA values in the ovary and ovarian bursa fluid decreased on the operated side. At 1 month after surgery, the values in ovary were normal but the values in ovarian bursa fluid were still low, suggesting that the source of ovarian GABA was not the oviduct. The variations observed in the present paper suggest an involvement of GABA in reproductive physiology.
\end{abstract}

\section{Introduction}

Since the discovery of $\gamma$-aminobutyric acid (GABA) and its synthesizing enzyme, glutamate decarboxylase (GAD; EC 4.1.1.15) in the mammalian brain, these substances have been considered to be associated with inhibitory synapses in the central nervous system (Roberts \& Frankel, 1950). However, there is also evidence suggesting that GABA and GAD occur in peripheral tissues, although their functions have not yet been clarified (Zachmann, Tocci \& Nyhan, 1966; Whelan, Scriver \& Mohyuddin, 1969; Wu, Saito, Wong \& Roberts, 1974; Okada, Taniguchi \& Shimada, 1976).

High concentrations of GABA in the rat ovary and oviduct have been reported (Martin del Río \& Latorre Caballero, 1980; Erdö, Rosdy \& Szporny, 1982). In addition, a high affinity GABA receptor has been identified in the rat ovary (Schaeffer \& Hsueh, 1982) and oviduct (Erdö \& Lapis, 1982), and variations of GABA content in the ovary and oviduct during pregnancy have been described (Erdö, 1984).

The aim of the present work was to determine whether changes in GABA content of the female rat genital tract correlate with physiological events.

\section{Materials and Methods}

Female Holtzman rats of $200-250 \mathrm{~g}$ body weight, maintained in $14 \mathrm{~h}$ light-10 h dark (lights on 06:00-20:00 h) were fed with Purina chow and had free access to water. Vaginal smear cytology was checked daily in the morning and only animals exhibiting at least three regular 4-day cycles were chosen. 
Oestrous cycle. The animals were used at different stages of the oestrous cycle. On the day of the experiment, they were killed by decapitation at various hours of the day; when time is not specified, animals were killed at 11:00 h. The different organs of the genital tract were dissected out under a stereoscopic microscope.

In some experiments, fluid from the ovarian bursa was also collected. GABA content was measured in all these samples.

Oviduct. Oviducts from animals at various stages of the oestrous cycle were dissected out, unrolled, divided into three portions (ovarian, medial and uterine) and assayed for GABA content.

In another experiment, the right oviduct was completely removed on the day of oestrus. Exposure of the tube was effected by medial abdominal incision under pentobarbitone sodium anaesthesia. The oviduct was removed after ligating the ovarian and uterine junctions. Special care was taken to avoid any impairment of the ovarian circulation. After the operation, vaginal smears were checked daily, and only animals which showed regular cycles were used for the experiment. They were killed on the day of oestrus, allowing at least 10 days after surgery. One group was also killed on the day of oestrus 1 month after surgery. In these experiments, the GABA contents of the ovary and ovarian bursa fluid of both sides were compared.

$G A B A$ assay. Tissues were homogenized in ice-cold twice-distilled water with an Ultraturrax homogenizer model T 18/10 (Jank \& Kunkel, Ika-Werk, Staufen, West Germany) and then centrifuged at $12000 \mathrm{~g}$ at $4^{\circ} \mathrm{C}$ for $20 \mathrm{~min}$.

Ovarian bursa fluid was used directly with no centrifugation.

GABA was measured in aliquants of the supernatant by a radioreceptor method which is based on the high-affinity binding of $\left[{ }^{3} \mathrm{H}\right]$ muscimol $(31.0 \mathrm{Ci} / \mathrm{mmol} ; 1 \mathrm{mCi} / \mathrm{ml}$; New England Nuclear, Boston, Massachussetts, U.S.A.) to a standardized preparation of GABA receptor from cerebellar membranes, and its displacement by endogenous GABA present in the tissues. The assay was carried out by the method of Bernasconi, Bittiger, Heid \& Martin (1980) with minor modifications: $400 \mu \mathrm{g}$ of membrane protein were used in each assay tube. The cerebellar membrane used in the assay was prepared according to Beaumont, Chilton, Yamamura \& Enna (1978).

Proteins were measured in the homogenates (Lowry, Rosebrough, Farr \& Randall, 1951). Data were evaluated by analysis of variance and comparisons between means were by the test of Tukey and Keuls (Snedecor \& Cochran, 1956) unless otherwise stated.

\section{Results}

GABA was found in all the organs of the female genital tract, showing the highest values in the oviduct (about $5 \mu \mathrm{g} / \mathrm{mg}$ protein) and the lowest in the ovary (50-100 $\mathrm{ng} / \mathrm{mg}$ protein). The values for uterus and vagina were $80-150 \mathrm{ng} / \mathrm{mg}$ protein.

\section{Oestrous cycle}

During most of the stages of the oestrous cycle, the ovarian content of GABA did not change, but on the day of oestrus at 11:00 h there was a significant increase (Fig. 1a).

The GABA content in the vagina also varied, being $86.00 \pm 5.76(n=15), 153.07 \pm 18.65$ $(n=12) \quad(P<0.01), 89.78 \pm 5.30 \quad(n=15)$ and $104.20 \pm 5.72 \quad(n=15) \mathrm{ng} / \mathrm{mg}$ protein at dioestrus- 1 , dioestrus- 2 , pro-oestrus and oestrus respectively.

The total GABA content of the oviduct fluctuated during the oestrous cycle. The highest values were found at 11:00 h of pro-oestrus; there was a slight decline until $06: 00 \mathrm{~h}$ of oestrus and then values increased again (Fig. 1b). 

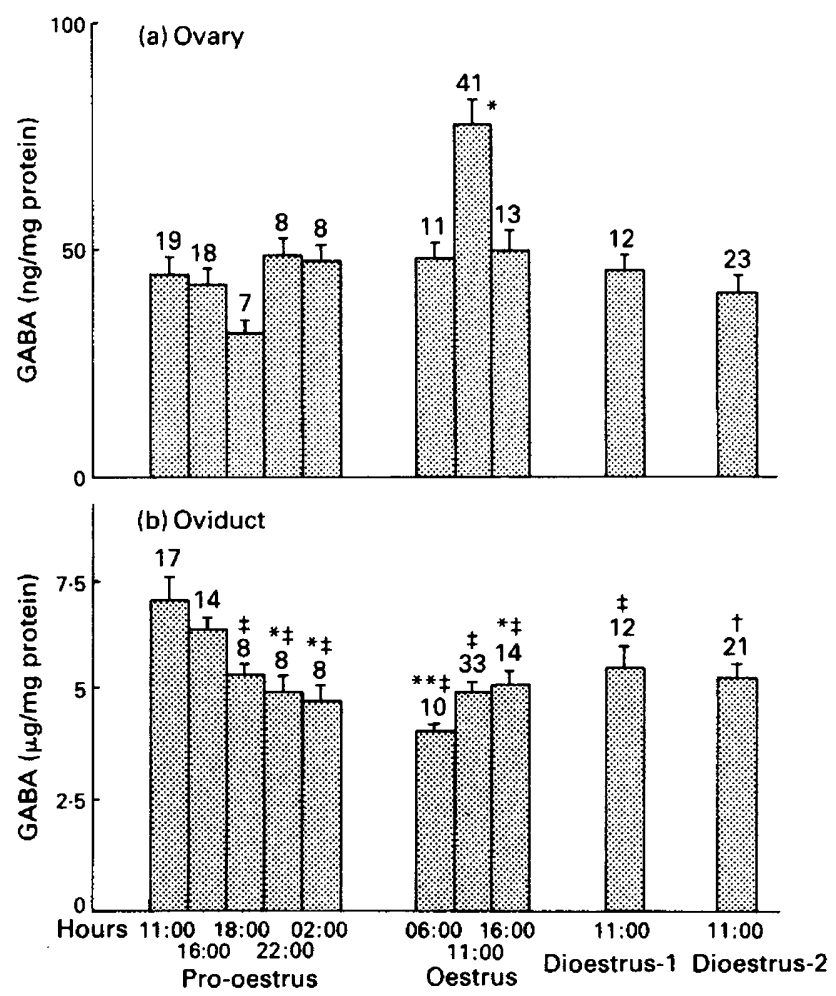

Fig. 1. GABA content in the (a) ovary and (b) oviduct during the oestrous cycle at different times of day. Values are the mean \pm s.e.m. for the number of observations indicated. (a) ${ }^{*} P<0.01$ compared with the other groups. (b) ${ }^{*} P<0.01$ and ${ }^{* *} P<0.05$ compared with values at $11: 00 \mathrm{~h}$ on pro-oestrus; $\uparrow P<0.05$ and $\ddagger P<0.01$ compared with values at $16: 00 \mathrm{~h}$ on pro-oestrus.

High values of GABA were found in the ovarian bursa fluid which also varied in the oestrous cycle. On dioestrus-2 GABA in ovarian bursa fluid showed the lowest values $(10.15 \pm 1.64 \mathrm{ng} / \mu \mathrm{l}$, $n=6)$ and from this day on, a continuous increase took place $(12.97 \pm 1.97 \mathrm{ng} / \mu \mathrm{l}, n=6$, for pro-oestrus and $18.04 \pm 4.40 \mathrm{ng} / \mu \mathrm{l}, n=6$, for oestrus), reaching the maximal values $(26.44 \pm 6.12 \mathrm{ng} / \mu \mathrm{l}, n=6)$ on dioestrus-1 $(P<0.05$ dioestrus-1 vs dioestrus-2).

There were no changes in the GABA content $(\mathrm{ng} / \mathrm{mg}$ protein) in the uterine horn $(109.78 \pm 12.05, \quad 126.80 \pm 13 \cdot 13, \quad 115.26 \pm 8.11$ and $134.19 \pm 8.52)$ or uterine cervix $(106 \cdot 31 \pm 10 \cdot 04,130 \cdot 25 \pm 8 \cdot 76,127 \cdot 29 \pm 11 \cdot 60,140 \cdot 09 \pm 9 \cdot 65)$ at dioestrus-1, dioestrus-2, pro-oestrus and oestrus, respectively.

\section{Oviduct}

A gradient of GABA concentration was observed: the values ( $\mu \mathrm{g} / \mathrm{mg}$ protein) were $6.87 \pm 0.79$ $(n=20)$ at the ovarian end, $5.64 \pm 0.71(n=19)$ in the medial portion, and 2.54 $\pm 0.29(n=18)$ at the uterine end $(P<0.05$ for ovarian and medial portions compared with uterine portion).

At 10 days after the removal of one oviduct, GABA values decreased in the ovary and ovarian bursa fluid in the operated side. By 1 month there was no difference in GABA content between the 


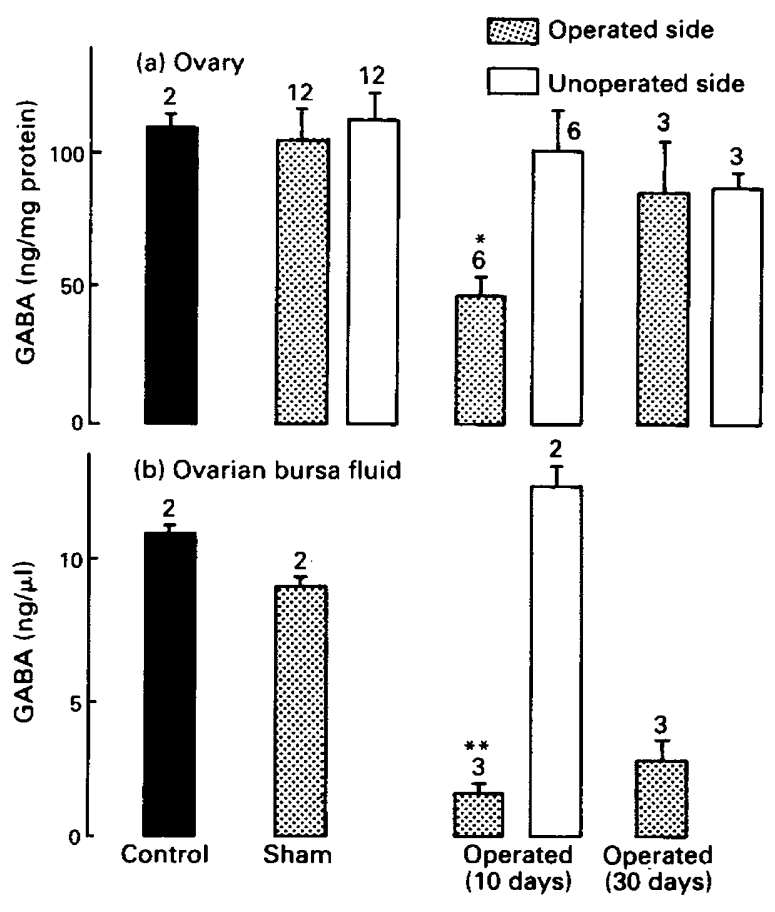

Fig. 2. GABA content in (a) ovary and (b) ovarian bursa fluid in control, sham-operated and operated rats in which the right oviduct was removed. Surgery was on the day of oestrus at 11:00 h. Animals were killed after 10 or 30 days at 11:00 h on the day of oestrus. Values are mean \pm s.e.m. for the number of animals used. ${ }^{*} P<0.05$ (paired $t$ test) and ${ }^{* *} P<0.001$ (unpaired $t$ test) $v s$ non-operated side.

ovaries of both sides, while GABA in ovarian bursa fluid was significantly lower in the operated side (Fig. 2).

\section{Discussion}

Our studies show that GABA is present in all the organs of the female genital tract of the rat. Since the structural localization of GABA in the genital tract has not yet been determined, a neuronal and/or non-neuronal localization of GABA should be considered. It is known that GABA is found in the neural tissue of the myenteric plexus in the digestive tract (Jessen, Mirsky, Dennison \& Burnstock, 1979), but a non-neuronal localization has also been described in the central nervous system (Iversen \& Kelly, 1975) and in the anterior lobe of the pituitary gland (Racagni et al., 1979). In addition, a study based on biochemical and immunochemical techniques indicates a neuronal origin for GABA in the oviduct and a non-neuronal origin for GABA in the ovary (Apud et al., 1984).

The method used in our experiments for the assay of GABA is based on its binding to purified cerebellar membranes and it is therefore possible that another compound with affinity for the GABA receptor was measured (Mitchell, Grieve, Dow \& Fink, 1983). However, this is probably not the case since the GABA content in the ovary and oviduct has already been measured by other techniques and the values found were similar to ours (Martín del Río, 1981; Okada, Taniguchi \& Baba, 1982; Apud et al., 1984).

Depending upon the different methods used to kill the animals, a post-mortem increase in 
GABA synthesis has been observed in the central nervous system (Tappaz, Brownstein \& Kopin, 1977; Van der Heyden \& Korf, 1978). In our studies of the genital tract, the animals were decapitated and GABA values were similar to those in which procedures that avoid the artificial increase of GABA were employed (Martín del Río, 1981; Erdö et al., 1982; Okada et al., 1982; Apud et al., 1984), showing that no post-mortem GABA synthesis occurs in the female genital tract.

Our studies also show an ovarian GABA surge during the morning of oestrus several hours after ovulation, suggesting a function for GABA in corpus luteum formation. Supporting these results, an ovarian GABA increase was found during pregnancy in the rat (Erdö, 1984). However, this change in GABA might also represent a trigger for the next cycle of follicular maturation.

During the oestrous cycle, the concentration of GABA in the ovarian bursa fluid changes in a way similar to that observed in the ovary. A higher content of GABA in fluid than in ovary can be accepted even assuming that $10 \%$ of the weight of liquid is due to proteins. These results, and those showing the high values of GABA in the oviduct, as well as the existence of a gradient of concentration in that organ, may suggest an oviducal origin of the ovarian GABA. In addition, when ovarian GABA values were maximal, oviducal values were minimal, and in the pregnant rat an increment of GABA in the ovary is accompanied by a GABA decrease in the oviduct (Erdö, 1984). However, in the experiments in which one oviduct was removed, ovarian GABA did not disappear completely as would be expected if the source of ovarian GABA had been the oviduct. The measurements at 10 and 30 days after surgery suggest that the ovary synthesizes its own GABA. Supporting these findings, GAD activity has been found in the ovary (Schaeffer \& Hsueh, 1982; Erdö, Kiss \& Szporny, 1984a) and an intrinsic origin for ovarian GABA has been demonstrated by means of subcutaneous explants (Apud et al., 1984).

The concentration of GABA in the vagina also changes during the oestrous cycle. A possible explanation for the surge observed on the day of dioestrus- 2 may be due to the high leucocyte content in the vaginal epithelium. Leucocytes have high GABA content (P. Louzan, unpublished data). Although we were not able to find variation in the GABA content in uterine cervix or uterine horn during the oestrous cycle, increased GABA in the uterus at oestrus was reported (Fernández Pardal, Gimeno \& Gimeno, 1984).

Our results show that GABA in the oviduct changes during the cycle, reaching the highest values in the morning of pro-oestrus. However, maximal values of GABA in the oviduct at early dioestrus have been reported (Martín del Río, 1981). This discrepancy, which may lead to a different interpretation of the results, cannot be presently explained. We observed maximal GABA values on the morning of pro-oestrus when blood oestrogens are also maximal. In addition, the GABA variations in the oviduct correlate well with serum oestrogen concentrations throughout the oestrous cycle (Smith, Freeman \& Neill, 1975). During pregnancy, when progesterone increases, levels of GABA in the oviduct decrease (Erdö, 1984). Taken together, these results suggest a close relation between GABA in the oviduct and steroids secreted by the ovary.

An involvement of GABA in intestinal peristalsis (Krantis, Costa, Furness \& Orbach, 1980) and in contractility of rabbit oviduct has been reported (Erdö, Riesz, Kárpáti \& Szporny, 1984b). On the other hand, in-vitro tubular motility is maximal at pro-oestrus and minimal at oestrus (Borda, Sterin-Borda, Gimeno, Sterin-Speziale \& Gimeno, 1975); we observed the same tendency in the variations of the oviducal GABA concentration. The temporal correlation between changes of motility and oviducal GABA might implicate GABA in the regulation of tubular motility.

The GABA variations in ovary and oviduct described in the present paper, supported by the presence of specific receptors in both organs (Schaeffer \& Hsueh, 1982; Erdö \& Lapis, 1982), suggest an active participation of this amino acid in the reproductive physiology of the female rat.

We thank Dr E. Lamuedra, L. Correa and G. Cozzi for technical assistance; and Dr P. Willshaw for reading the manuscript. This work was supported by Fundación Instituto de Neurobiología and Consejo Nacional de Investigaciones Científicas y Técnicas, Argentina. 


\section{References}

Apud, J.A., Tappaz, M.L., Celotti, F., Negri-Cesi, P., Masotto, C. \& Racagni, G. (1984) Biochemical and immunochemical studies on the GABAergic system in the rat fallopian tube and ovary. J. Neurochem. 43, $120-125$.

Beaumont, K., Chilton, W.A., Yamamura, H.I. \& Enna, S.J. (1978) Muscimol binding in rat brain: association with synaptic GABA receptors. Brain Research 148, $153-162$.

Bernasconi, R., Bittiger, H., Heid, J. \& Martin, P. (1980) Determination of GABA levels by a ${ }^{3} \mathrm{H}$-muscimol radioreceptor assay. $J$. Neurochem. 34, 614-618.

Borda, E., Sterin-Borda, L., Gimeno, M.F., SterinSpeziale, N. \& Gimeno, A.L. (1975) Motility of the rat oviductal tract isolated in different stages of the sex cycle. Int. J. Fertil. 20, 170-176.

Erdö, S.L. (1984) Alteration of GABA levels in ovary and fallopian tube of the pregnant rat. Life Sci. 34, $1879-1884$.

Erdö, S.L. \& Lapis, E. (1982) Presence of GABA receptors in rat oviduct. Neurosci. Lett. 33, 275-279.

Erdö, S.L., Rosdy, B. \& Szporny, L. (1982) Higher GABA concentrations in Fallopian tube than in brain of the rat. J. Neurochem. 38, 1174-1176.

Erdö, S.L., Kiss, B., Szporny, L. (1984a) Comparative characterization of glutamate decarboxylase in crude homogenates of oviduct, ovary and hypothalamus. $\dot{J}$. Neurochem. 43, 1532-1537.

Erdö, S.L., Riesz, M., Kárpáti, E. \& Szporny, L. (1984b) GABA $\beta$ receptor-mediated stimulation of the contractility of isolated rabbit oviduct. Eur.J. Pharmacol. 99, 333-336.

Fernández Pardal, J., Gimeno, M.F. \& Gimeno, A.L. (1984) The presence of GABA in ovarian, tubal and uterine rat tissue and the influence of estrogens. IRCS Med. Sci. 12, 706.

Iversen, L.L. \& Kelly, J.S. (1975) Uptake and metabolism of $\gamma$-aminobutyric acid by neurones and glial cells. Biochem. Pharmac. 24, 933-938.

Jessen, K.R., Mirsky, R., Dennison, M.E. \& Burnstock, G. (1979) GABA may be a neurotransmitter in the vertebrate peripheral nervous system. Nature, Lond. 281, $71-74$.

Krantis, A., Costa, M., Furness, J.B. \& Orbach, J. (1980) Gamma-amino-butyric acid stimulates intrinsic inhibitory and excitatory nerves in the guinea-pig intestine. Eur. J. Pharmacol. 67, 461-468.

Lowry, O.H., Rosebrough, N.J., Farr, A.L. \& Randall, R.J. (1951) Protein measurement with the Folin phenol reagent. J. biol. Chem. 193, 265-268.

Martín del Río, R. (1981) Gamma-aminobutyric system in rat oviduct. J. biol. Chem. 256, 9816-9819.

Martín del Río, R. \& Latorre Caballero, A. (1980) Presence of $\gamma$-aminobutyric acid in rat ovary. $J$. Neurochem. 34, 1584-1586.
Mitchell, R., Grieve, G., Dow, R. \& Fink, G. (1983) Endogenous GABA receptors ligands in hypophysial portal blood. Neuroendocrinology 37, 169-176.

Okada, Y., Taniguchi, H. \& Shimada, C. (1976) High concentration of GABA and high glutamate decarboxylase activity in rat pancreatic islets and human insulinoma. Science, N.Y. 194, 620 622 .

Okada, Y., Taniguchi, H. \& Baba, S. (1982) High concentration of GABA in the pancreatic islets with special emphasis on $\beta$ cells. In Problems in $G A B A$ Research from Brain to Bacteria, pp. 379-386. Eds Y. Okada \& E. Roberts. Excerpta Medica, Amsterdam.

Racagni, G., Apud, J.A., Locatelli, V., Cocehi, D., Nistico, G., Di Giorgio, R.M. \& Müller, E.E. (1979) GABA of CNS origin in the rat anterior pituitary inhibits prolactin secretion. Nature, Lond. 281, $575-578$.

Roberts, E. \& Frankel, S. (1950) Gamma-aminobutyric acid in the brain, its formation from glutamic acid. $J$. biol. Chem. 187, 55-63.

Schaeffer, J.M. \& Hsueh, A.J. (1982) Identification of Gamma-amino-butyric acid and its binding sites in the rat ovary. Life Sci. 30, 1599-1604.

Smith, M.S., Freeman, M.E. \& Neill, J.D. (1975) The control of progesterone secretion during the oestrous cycle and early pseudopregnancy in the rat: prolactin, gonadotropin and steroid levels associated with rescue of the corpus luteum of pseudopregnancy. Endocrinology 96, 219-226.

Snedecor, G.W. \& Cochran, W.G. (1956) Statistical Methods. Iowa State University Press, Ames.

Tappaz, M., Brownstein, M.J. \& Kopin, J.J. (1977) Glutamate decarboxylase (GAD) and gammaaminobutyric acid (GABA) in discrete nuclei of hypothalamus and substantia nigra. Brain Res. 125, 109-121.

Van der Heyden, J.A.M. \& Korf, J. (1978) Regional levels of GABA in the brain: rapid semiautomated assay and prevention of postmortem increase by 3-mercapto-propionic acid. J. Neurochem. 31, 197-203.

Whelan, D.T., Scriver, C.R. \& Mohyuddin, F. (1969) Glutamic acid decarboxylase and gammaaminobutyric acid in mammalian kidney. Nature, Lond. 224, 916-917.

Wu, J.Y., Saito, K., Wong, E. \& Roberts, E. (1974) Studies of L-glutamate decarboxylase and $\gamma$ aminobutyrate transaminase from various tissues and species. Trans. Am. Soc. Neurochem. 5, 112.

Zachmann, M., Tocci, P. \& Nyhan, W.L. (1966) The occurrence of $\gamma$-aminobutyric acid in human tissues other than brain. J. biol. Chem. 241, 1355-1358.

Received 3 October 1985 